DOI:

\title{
Numerical Study of Induced Condensation upon Mixing Flows of Water-Steam Flow in a Tee-Junction Pipe
}

\author{
Khaled Yousef ${ }^{1,}$, , Fatma Saleh ${ }^{2}$ and Ahmed Hegazy ${ }^{1}$ \\ ${ }^{1}$ Mechanical Engineering Department, Menoufia University, Shebin El-Kom, Egypt \\ ${ }^{2}$ Ministry of Water Resources, Egypt \\ (Corresponding author: khyousef@msu.edu andng_khalid@yahoo.com)
}

\begin{abstract}
Tee-junction is a device used in pipes to transfer, mixing of two dissimilar fluids of different parameters or either same type with varying parameters. The design of the tee-pipe affects its function. The present paper introduces a numerical study of two-phase flow mixing in a T-junction pipe. Water liquid streams in the horizontal main pipe of a $\mathrm{T}$-junction while saturated steam is drawn from the other pipe branch (it lies in a vertical plane). That results in water liquid and steam mixing with steam condensation, and the mixture is directed to exit from the main pipe. The computational model is validated first with the experimental data for a single-phase flow. Two junction angles $90^{\circ}$ and $45^{\circ}$ between the main pipe and branched pipes are utilized for the $\mathrm{T}$-junction. Different mass ratios for water liquid and steam are examined in the main pipe and branched pipes. Also, various turbulence models are utilized to select the best suitable model for predicting such flows. The comparison ensured the superiority of the realizable $\mathrm{k}-\varepsilon$ model for the present two-phase flow mixing. The obtained results reveal that the T-junction pipe with a junction angle of $45^{\circ}$ achieves improved operational performance compared to the pipe with the junction angle of $90^{\circ}$. This result shows that the incline of the branch pipe could induce more heat transfer on the area of the $\mathrm{T}$-junction, which inevitably could condensate more steam from the branch pipe. The T-junction pipe with a $45^{\circ}$ angle can condense all the mixed steam in shorter pipe lengths with lower pressure loss at the same operational conditions compared to the $90^{\circ}$ junction angle pipe. Moreover, for constant mass flow rates in the main and branched pipes, an increase in their diameters results in a remarkable enhancement of steam condensation.
\end{abstract}

Keywords: Two phase-flow, T-junction, Mixing, Condensation

\section{Introduction}

Mixing is defined as the process of thoroughly combining different materials to produce a homogenous final product. Also, mixing can be used to reduce the inhomogeneity (such as concentration, phase interaction, and temperature) to achieve the desired property. The mixing process includes mass transfer, reaction, desired product properties and controlling parameters in industrial applications. For obtaining uniform mixing, two conditions should exist. The first condition is a convective flow should be obtained to get rid of any dead and stagnant zones. Secondly, a mixing zone with a high fluid shear is required to break the resulted homogeneities. The mixing of different materials with different phases has been used in various industrial applications. Besides, the use of the mixing process to get a certain degree of flow homogeneity, it is also being utilized in the industry to improve heat and mass transfer, and phase change process for two-phase flow interaction.
In the present study, mixing steam and water liquid results in condensation due to phase change from steam into water liquid. This process is complicated as various generating effects are created due to the condensation phenomenon. Condensation generates a vacuum region, which increases the induced turbulence and it also generates the flow fluctuations. These flow fluctuations may transmit to the carrying pipe. Furthermore, condensation produces thermal fluctuation and disturbance in the mixing region, which should be carefully considered in the CFD simulation $[1,2]$.

Few researchers studied theoretically and experimentally the mixing process in $\mathrm{T}$-junction. Frank et al. [3] studied numerically the thermal mixing of two turbulent flows. The CFD results predicted the thermal stripping phenomenon's existence in the T-pipe. Furthermore, CFD results were in good agreement with the obtained experimental data. Benyamina et al. [4] discussed the 


\section{Khaled Yousef, Fatma Saleh and Ahmed Hegazy "Numerical Study of Induced Condensation upon Mixing Flows of Water-Steam Flow in a Tee-Junction Pipe”}

turbulent mixing in a T-junction using large eddy simulation (LES). They concluded that to get numerical results close to the experimental data, the required mesh resolution should consider the Taylor micro-scale length. They noted that fine meshes must be used to capture fluctuations accurately in the shear layer near the center of the mixing zone.

Experiments on a T-junction of a small-scaled rectangular cross-section were presented by Masuda et al. [5]. In this work, the mixing was studied at high pressure with very large temperature differences. The flow conditions were in the laminar region and the effect of buoyancy forces was noticed which improved the mixing process by destabilizing the flow regimes. More recently, an experimental investigation of thermal mixing phenomena in a $\mathrm{T}$ junction pipe was carried out by Mei-Shiue Chen et al. [6]. This study analyzed the changes in the flow rate in the main and branch pipes. Also, the study analyzed the reverse flow effect of cold-water shock on the wall of the main pipe. Moreover, this study discussed the effect of high thermal fluctuations in the wall (main pipe) causing strong thermal stresses. It is noticed that the reverse flow created large thermal wall stresses.

Maruyama et al. [7-9] presented a series of studies for the jet injection of fluid into a pipeline over the first twelve pipe diameters from the injection point in T-junction. First, Maruyama et al. [7] presented an experimental investigation for the two fluid streams mixing at the $\mathrm{T}$-junction. The conditions required for the optimum mixing were obtained analytically. In another study, Maruyama et al. [8] found out a mixing condition based on the temperature distribution across the main pipe diameter. The mixing conditions at an oblique branch for two fluid streams as a function of the branch angle was described. The main conclusions of this study [8] are the oblique branch should be at an angle of $45^{\circ}$ to the main pipe for rapid mixing. In a complementary study, Maruyama et al. [9] investigated the optimum conditions for the rapid mixing of two fluid streams in turbulent pipe flow for single and dual injection. They concluded that mixing depends on the flow patterns created by the jet impingement. These patterns depend on the degree of penetration of the jet into the main flow stream.

Hosseini et al. [10] presented an experimental model including the T-junction with a $90^{\circ}$ bend. They analyzed the mixing phenomenon based on the real operating design of the Phoenix reactor. The temperature and velocity data showed that a $90^{\circ}$ bend had a strong effect on the fluid mixing mechanism and the momentum ratio between the main velocity and the branch velocity of the T-junction. To better observe the mixing phenomena, Zughbi [11] carried out numerical and experimental investigations of the mixing inside tees. Hot water introduced through the branch pipe was mixed with cold water flowing in the main pipe. The length of the main pipe downstream of the jet inlet required to achieve $95 \%$ mixing is a function of the velocity ratio. Numerical results showed a good agreement with experimental results. The angle of the jet had a significant effect on the mixing length. Moreover, it showed that mixing depends on the flow patterns created by the jet impingement. Turbulent mixing phenomena have been investigated in a T-junction by Zboray et al. [12]. Their study conducted an experiment named ETHZ test case to study the problems of thermal fatigue that may be encountered in nuclear power plant operation. Their experiments were accompanied by numerical simulations and good agreements were obtained.

Hegazy et al. [13] proposed a new framework for using the cooling seawater of the condenser of a steam power plant for desalination. In this new system, the warm saline water left the condenser is allowed to flow into a barometer tube. This warm saline water flows to a tight evaporator under vacuum and some water vapor is flashed. The produced water vapor continued to reach the tip of an inverted Upipe. This tip of the inverted U-pipe is connected to an entraining tube and the siphon flow is used to produce a vacuum. The results of this analytical study for predicting the proposed system performance have revealed that a relatively high value of producing freshwater rates can be achieved by selecting the appropriate dimensions of the proposed system. This system has inspired us to study the mixing process characteristics of the flashed water vapor with the flowing water liquid at the tip of the inverted U-pipe. They recommended that their study is necessary to improve and manufacture this system.

Nimadge and Chopade [14] designed an experimental set-up and performed a CFD analysis to establish velocity and pressure characteristics for the water liquid flow through the T-junction of the pipe. The main conclusions of this work were the velocity of water flow is strongly influenced by the $90^{\circ}$ angle of the $\mathrm{T}$ - junction of the pipe. In addition, the velocity and pressure of water tend to decrease, after passing through T- junction of pipe. The energy loss can be decreased by decreasing the angle of $\mathrm{T}$ - junction of pipe. Numerical analysis by using CFD simulation of fluid flow in T-Junction pipe was performed by Ferede [15]. This study ensued the effect of Tjunction angle on the generated flow field after mixing of the two junction streams. Ren et al. [16] performed an experiment of steam condensation in a 


\section{Khaled Yousef, Fatma Saleh and Ahmed Hegazy "Numerical Study of Induced Condensation upon Mixing Flows of Water-Steam Flow in a Tee-Junction Pipe”}

T-junction with an angle of $45^{\circ}$ and under waterinjected conditions. They analyzed the process of cooling water injection from the branch pipe into a horizontal main pipe in which the steam is flowing. The main conclusion of the experiment ensured that the incline branch offered more directly contact condensation and more heat transfer when sub-cooled water was injected.

It appears from the available previous studies that the steam condensation due to steam and water liquid mixing in the $\mathrm{T}$-junction pipe is rarely studied. The present work aims to study numerically the effect of the $\mathrm{T}$-junction angle on the steam and water liquid mixing in the presence of steam condensation. In this work, the mixing of water liquid and vapor at the $\mathrm{T}$ junction of a vertical pipe is simulated using the commercial package FLUENT. This simulation leads to predicting the flow characteristics inside the T-junction and studying the head loss suffered by the mixture on passing through the junction.

\section{Mathematical Methodology}

The flow of most fluids can be mathematically described by the use of continuity equation and momentum equations. The momentum equations are sometimes also referred as Navier-Stokes equations. They are most commonly used mathematical equations to describe many flow situations. The steady Navier Stokes equations are solved together with the turbulence and two-phase flow model equations. The mixture model integrated with the evaporation-condensation model is used in this study for the two-phase flow computations. These models ensured the most appropriate and economical approach for the homogeneous flow simulation [17].

\subsection{Computational Domain}

The detailed computational domain is carried out at a connection of two pipes of equal inner diameter $\left(D_{\text {in }}=0.05 \mathrm{~m}\right)$ for both the main and branch pipe. In addition, the effect of the pipe cross-sectional area on the steam condensation is considered. The length of the main pipe before the junction is equal to $1 \mathrm{~m}$ which is $20 \mathrm{D}_{\text {in }}$, to obtain fully developed flow conditions. The length of the main pipe after the junction is $0.5 \mathrm{~m}$, which is equivalent to $10 D_{i n}$. The length of the side branch pipe (steam pipe) is also 0.5 $\mathrm{m}$ which is $10 D_{\text {in }}$ as shown in Figure (1). The water is flowing from left to right with a static temperature of $300 \mathrm{~K}$ and at atmospheric pressure while the saturated steam is drawn down through the branch pipe at the atmospheric pressure. The steam and water liquid flows are combined and mixed after the T-junction. The exit mixture temperature and flow conditions after the mixing point depend on the inlet flow properties and steam to water liquid mass ratios.

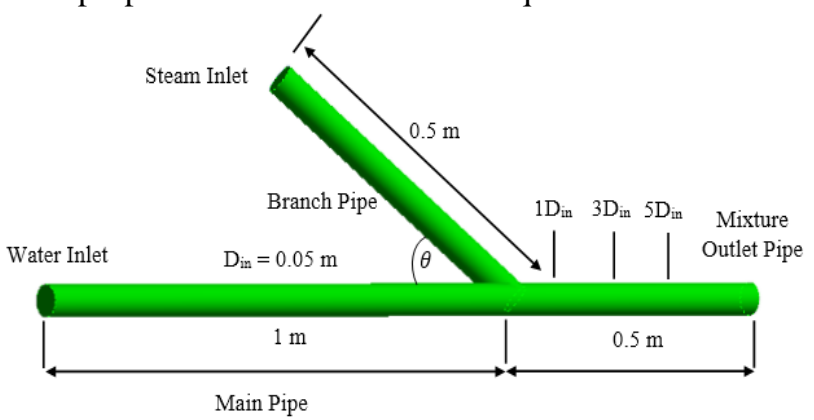

Figure (1) Computational domain to the main and branch pipes at $45^{\circ} \mathrm{T}$-junction

\subsection{Governing Equations}

Steady-state 3-D CFD computations were accomplished for the T-Junction depicted in Figure (1). The properties of water liquid is assumed to be constant while the steam properties are taken to be functions of temperature. User defined functions compiled by FLUENT are used to define the steam property in each cell of the mesh as a function of its temperature. Steam dryness fraction is equal to 1 at its steam inlet and its reverse back flow is taken to be zero at the pipe exit. Also, it is considered that the mixing is homogenous and no velocity gradient between the two phases. The general differential equations governing the turbulent flow in mixing pipes are given as $[\mathbf{1 7}, \mathbf{1 8}]$

Continuity

$$
\operatorname{div}(\rho u)=0
$$

The momentum conservation equations

$$
\begin{aligned}
\operatorname{div}(\rho u u) & =-\frac{\partial p}{\partial x}+\operatorname{div}(\mu \operatorname{grad} u) \\
+ & {\left[-\frac{\partial \rho u^{2 \prime}}{\partial x}-\frac{\partial \rho u^{\prime} v^{\prime}}{\partial y}-\frac{\partial \rho u^{\prime} w^{\prime}}{\partial z}\right] } \\
\operatorname{div}(\rho v u) & =-\frac{\partial p}{\partial y}+\operatorname{div}(\mu \operatorname{grad} v) \\
& +\left[-\frac{\partial \rho u^{\prime} v^{\prime}}{\partial x}-\frac{\partial \rho v^{2 \prime}}{\partial y}-\frac{\partial \rho v^{\prime} w^{\prime}}{\partial z}\right] \\
\operatorname{div}(\rho w u) & -\frac{\partial p}{\partial z}+\operatorname{div}(\mu \operatorname{grad} w) \\
+ & {\left[-\frac{\partial \rho u^{\prime} w^{\prime}}{\partial x}-\frac{\partial \rho v^{\prime} w^{\prime}}{\partial y}-\frac{\partial \rho w^{2 \prime}}{\partial z}\right] }
\end{aligned}
$$




\section{Khaled Yousef, Fatma Saleh and Ahmed Hegazy "Numerical Study of Induced Condensation upon Mixing Flows of Water-Steam Flow in a Tee-Junction Pipe”}

The statistical energy conservation equation

$$
\operatorname{div}(\rho E u)=\operatorname{div}(K \operatorname{grad} T)+\Phi+
$$

$$
\left[-\frac{\partial \overline{\rho u^{\prime} E^{\prime}}}{\partial x}-\frac{\partial \rho v^{\prime} E^{\prime}}{\partial y}-\frac{\partial \rho_{w^{\prime} E^{\prime}}}{\partial z}\right]
$$

Where $u, v$ and $w$ are the flow velocity components, $\boldsymbol{u}^{2}=\boldsymbol{u}^{2}+\boldsymbol{v}^{2}+\boldsymbol{w}^{2} . T$ is the static temperature and $\boldsymbol{\mu}$ is the dynamic viscosity. $\boldsymbol{\rho}$ is the mixture density and $\boldsymbol{p}$ is the static pressure. $\boldsymbol{E}=\boldsymbol{h}-\frac{\boldsymbol{p}}{\boldsymbol{\rho}}+$ $\frac{\left(u^{2}+v^{2}\right)}{2}$ while the function of dissipation is $\boldsymbol{\Phi}$ and $\boldsymbol{h}$ is taken as the sensible enthalpy, $\boldsymbol{h}=\sum_{\boldsymbol{i}} \boldsymbol{Y}_{\boldsymbol{i}} \boldsymbol{h}_{\boldsymbol{i}}$ and $\boldsymbol{h}_{\boldsymbol{i}}=\int_{\boldsymbol{T}_{\boldsymbol{r e f}}}^{\boldsymbol{T}} \boldsymbol{C}_{\boldsymbol{p} \boldsymbol{i}} \boldsymbol{d T}$ where $\boldsymbol{T}_{\boldsymbol{r e f}}$ is considered as the reference temperature and taken to be $298.15 \mathrm{~K}$.

\subsection{Turbulence Modeling}

The choice of turbulence model is very critical in any CFD simulation. In the present study, the CFD simulation of superior different turbulence models

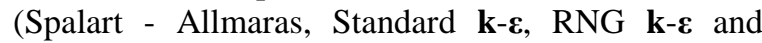
Realizable k-e) are executed and compared with the results of the ETHZ experiment reported in [12]. Generally, for comparing the data from experimental and theoretical analysis of the temperature fields, the nondimensional quantities are mostly utilized. The used nondimensional quantity is known as mixing scalar which is defined as $T^{*}=\frac{T-T_{\text {cold }}}{T_{\text {hot }}-T_{\text {cold }}}$ where $T_{\text {hot }}, T_{\text {cold }}$ are the hot and cold temperatures of water in the main and branch pipes inlets, respectively. The comparative study of the abovementioned turbulence models is executed at $0.025 \mathrm{~m}$ before and after the mixing region centerline. The realizable k- $\boldsymbol{\varepsilon}$ model is the most suitable for the present study as its results have a close agreement with the ETHZ experiment as shown in Figure (2).

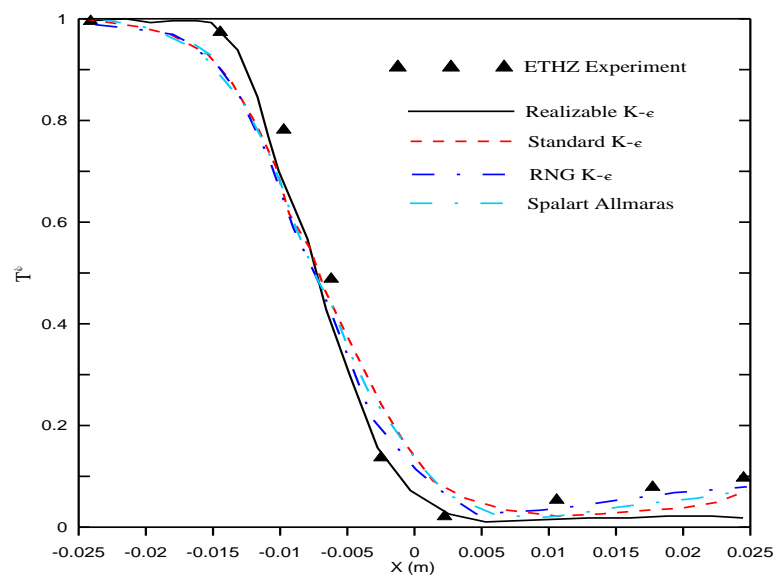

Figure (2) mixing scalar along the distance $0.025 \mathrm{~m}$

\section{$\left(5 D_{i n}\right)$ before and after the T-junction by using different turbulence models}

In the present study, the realizable $\boldsymbol{k}-\boldsymbol{\varepsilon}$ model in mixture form is utilized for computing the turbulence fields based on the comparison depicted in Figure (2). The realizable $\boldsymbol{k}-\boldsymbol{\varepsilon}$ model can provide a superposing performance in many complicated flows. Also, this turbulent model is characterized over the other turbulence models as it contains a new formulation for the calculating turbulent viscosity and a new transport equation for the dissipation rate $\boldsymbol{\varepsilon}$ is used $[17,19,20]$. The turbulent kinetic energy and the dissipation rate equations are

$$
\begin{gathered}
\frac{\partial}{\partial x_{i}}\left(k \rho u_{i}\right)=\frac{\partial}{\partial x_{i}}\left[\left(\mu+\frac{\mu_{t}}{\sigma_{k}}\right) \frac{k \partial}{\partial x_{i}}\right]+ \\
G_{k}+G_{b}-\rho \varepsilon-Y_{M}+S_{k} \\
\frac{\partial}{\partial x_{i}}\left(\rho u \varepsilon_{i}\right)=\frac{\partial}{\partial x_{i}}\left[\left(\mu+\frac{\mu_{t}}{\sigma_{\varepsilon}}\right) \frac{\varepsilon \partial}{\partial x_{i}}\right]+ \\
\rho C_{1} \varepsilon S-\rho C_{2} \frac{\varepsilon}{k+\sqrt{v \varepsilon}}+C_{1 \varepsilon} \frac{\varepsilon}{k} C_{\varepsilon 3} G_{b}+S_{\varepsilon}
\end{gathered}
$$

In the mixture turbulence model, the same turbulence field are given to all phases. That means that all phase properties are replaced with mixture properties in Eqs. (1) to (7). $\boldsymbol{G}_{\boldsymbol{k}}$ is the turbulent kinetic energy generation due to the mean velocity gradients while $\boldsymbol{G}_{\boldsymbol{b}}$ is the of turbulence kinetic energy generation due to buoyancy. $\boldsymbol{S}_{\boldsymbol{k}}$ and $\boldsymbol{S}_{\boldsymbol{\varepsilon}}$ are user-defined source terms. The other constants in the equations are $[\mathbf{1 8 , 1 9 ]}$,

$$
\begin{aligned}
C_{1} & =\max \left[0.43, \frac{\eta}{\eta+5}\right], \quad \eta=S \frac{\varepsilon}{k}, \\
S & =\sqrt{S 2_{i j} S_{i j}}
\end{aligned}
$$

In turbulence modeling, $\mu_{t}=\rho C_{\mu} \frac{k^{2}}{\varepsilon}, \quad \mu_{e f f}=\mu+$ $\mu_{t}$

The favorable features of the considered turbulence model as discussed earlier is $\boldsymbol{C}_{\boldsymbol{\mu}}$ does not have fixed value and can be correlated as $[\mathbf{1 8 , 1 9 ]}$,

$$
\begin{aligned}
& C_{\mu}=\frac{1}{A_{0}+A_{s} \frac{k U^{*}}{\varepsilon}}, U^{*}=\sqrt{S_{i j} S_{i j}+\hat{\Omega}_{i j} \hat{\Omega}_{i j}} \\
& \hat{\Omega}_{i j}=\bar{\Omega}_{i j}-\varepsilon_{i j k} \omega_{k}
\end{aligned}
$$




\section{Khaled Yousef, Fatma Saleh and Ahmed Hegazy "Numerical Study of Induced Condensation upon Mixing Flows of Water-Steam Flow in a Tee-Junction Pipe”}

Here, $\overline{\boldsymbol{\Omega}}_{\boldsymbol{i} \boldsymbol{j}}$ is the rotation tensor rate, with angular velocity $\omega_{k}$ and $\quad A_{0}=4.04, A_{s}=\sqrt{6} \cos \varphi$, $\varphi=\frac{1}{3} \cos ^{-1}(\sqrt{6} W), \quad W=\frac{s_{i j} s_{j k} s_{k i}}{\tilde{S}^{3}}, \quad \tilde{S}=$ $\sqrt{S_{i j} S_{i j}}, S_{i j}=\frac{1}{2}\left(\frac{\partial U_{i}}{\partial x_{j}}+\frac{\partial U_{j}}{\partial x_{i}}\right)$. In the current study, $C_{1 \varepsilon}=1.44, C_{2}=1.9, \sigma_{k}=1.0$, and $\sigma_{\varepsilon}=1.2$. The cell volume fraction for the phase is $\alpha$, and all phases volume fraction summation is equal to 1 , i.e. $[17,21]$

$$
\sum_{j=1}^{n} \alpha_{j}=1
$$

In water liquid and steam flow, in the fully water celled, the volume fraction of water, $\alpha_{w}$, is 1 while $\alpha_{s}$ is taken to be 0 . For calculating the secondary and primary phase's volume fractions, FLUENT $^{\circledR}$ solves a continuity equation for the secondary phase while Eq. (10) is utilized for the primary phase. In the condensation process, the water liquid is generated from steam due to phase change. So, the steam is considered as the primary phase and the water liquid is taken to be the secondary phase. The continuity volume fraction equation for the secondary liquid phase can be written as follows [17]

$\nabla \cdot \alpha_{w} \rho \vec{v}_{w}=\sum_{j=1}^{n} \dot{\mathrm{m}}_{w-s}-\dot{\mathrm{m}}_{s-w}$

$\dot{\mathrm{m}}_{w-s}, \dot{\mathrm{m}}_{s-w}$ is a mass source term that represents the mass transfer rate from water liquid to steam in case of evaporation or mass transfer rate from steam to water liquid in case of condensation. The average velocity of the mixture is, $\vec{v}_{m}=\frac{\sum_{j=1}^{n} \alpha_{j} \rho_{j} \vec{v}_{j}}{\rho_{m}}$ and the mixture density can be calculated by using the arithmetic mean of all phase densities

${ }^{\prime} \rho_{m}=\sum_{j=1}^{n} \alpha_{j} \rho_{j}$. All the mixture properties are correlated like the mixture density calculations.

\subsection{Initial and Boundary Conditions}

Boundary conditions specify the flow and thermal variables on the boundaries of the physical domain. Figure (1) shows the boundary conditions utilized in the present study. The mass flow inlet is applied for each phase and the mixture temperature is specified at the inlets of the steam and water of the T-pipe. The inlet turbulent intensity is taken to be $5 \%$ and the velocity profile at inlet is uniform. Reynolds number for the water liquid inlet flow ranges from 2860 to 11440 while it ranges between 100-1700 for the steam inlet. The pressure outlet boundary condition is specified as a constant value and equal to zero-gauge pressure at the outlet pipe and the backflow volume fraction is set to water liquid in case of reverse flow. The isolated wall of the duct has been set as hydraulically smooth walls with non-slip boundary conditions applied for both steam and water liquid phases. Enhanced wall functions are favorable in case of high thermal gradient near the wall and this wall treatment is considered in the present simulation for boundary layer capturing.

\subsection{Computational mesh}

Several mesh types have been tried to assess the grid dependence study. Tetrahedron mesh is more efficient than cut cell and it has a close agreement with the experimental results [12], as shown in Figure (3). For the present CFD computations, a grid independence study is performed and fine tetrahedral cells are used as depicted in Figure (4). The fine tested grid size is 573,950 . The fine mesh is utilized for the current computational calculations as it has the best agreement with ETHZ experimental data for single phase flow [12]. Furthermore, the validation is performed for single phase flow as shown in Figures (2), (3), and (4) while the two phase flow model validation with the experimental data reported in [16] is presented in Figure (5). The branched injected water mass flow rate is changed in the range of 100$500 \mathrm{~kg} / \mathrm{hr}$ and it is presented on the horizontal axis while the steam flow rate in the main pipe is kept constant, $\dot{\mathrm{m}}_{\mathrm{s}}=0.014 \mathrm{~kg} / \mathrm{s}$. The steam condensation mass flow rate is depicted on the vertical axis. The present two phase flow model can capture the steam condensation mass flow rate within a maximum deviation of $14 \%$. This deviation between the present CFD and data reported in [16] may be attributed to a longer downstream pipe is used in the experiment. This longer downstream pipe gives more time and space for the steam to be condensed.

\subsection{Computational procedure}

In the present simulation, the continuity, momentum, and energy equations are solved with the mixture and evaporation-condensation models in a threedimensional domain using Ansys FLUENT ${ }^{\circledR}$. Also, a quick discretization and first-order upwind scheme are used for all conservation equations to save computational time. For more accurate results, the third-order MUSCL discretization scheme is used. The coupled scheme is used for pressure-velocity coupling and the pressure is calculated with the presto scheme, as it is recommended for two-phase complex flow. The coupled algorithm solves the momentum and pressure-based continuity equations together which make the solution robust and more efficient over the segregated solution scheme. The used solver is pressure-based and the flow is steady 


\section{Khaled Yousef, Fatma Saleh and Ahmed Hegazy "Numerical Study of Induced Condensation upon Mixing Flows of Water-Steam Flow in a Tee-Junction Pipe”}

state. The gravitational acceleration is set equal to $9.81 \mathrm{~m} / \mathrm{s}^{2}$ in the vertical direction to account for the buoyancy effect with the density gradient. To achieve the steady-state convergence, different pseudo time steps are applied to the fluid (flow domain) and solid zones (pipe walls) of the computational domain. The selected pseudo time scale factors for fluid and solid zones are 0.7 and 1 , respectively. The pseudotransient fashion is recommended for the complex two-phase flow which accounts for high mass transfer through simulation.

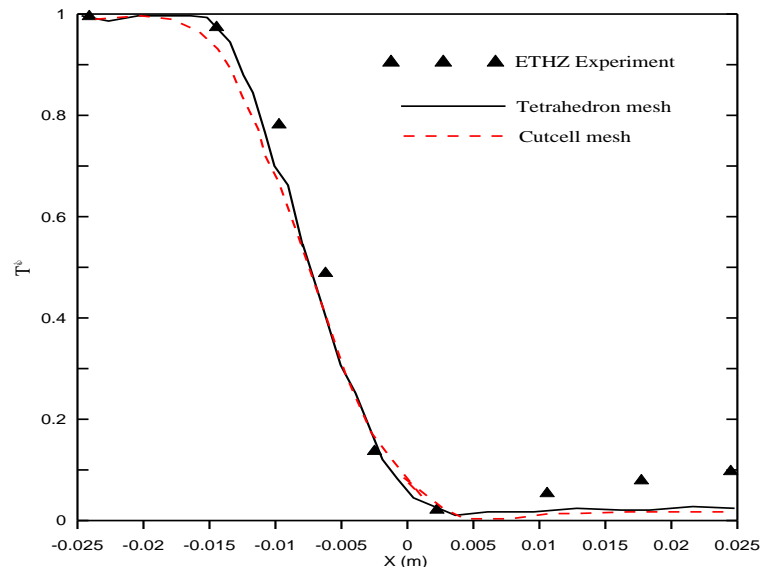

Figure (3) Mixing scalar along with the distance $0.025 \mathrm{~m}\left(5 D_{\text {in }}\right)$ before and after the T-junction using two mesh types.

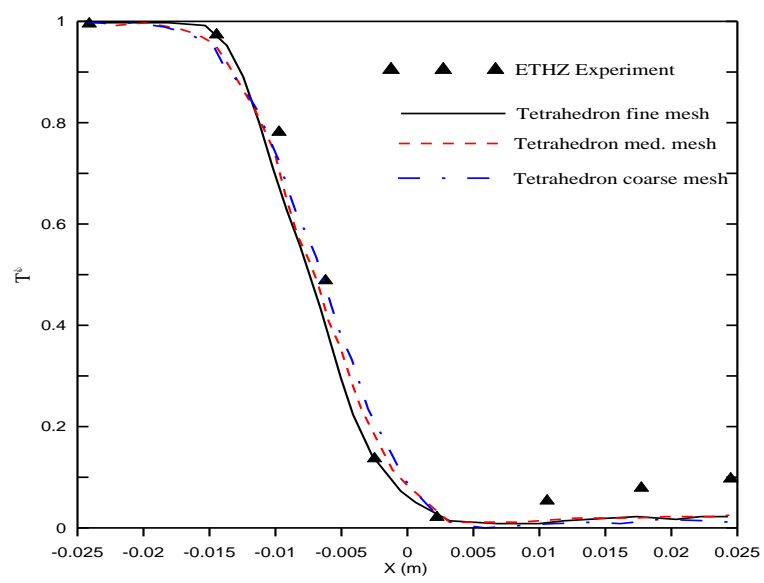

Figure (4) Mixing scalar along the distance $0.025 \mathrm{~m}$

$\left(5 D_{\text {in }}\right)$ before and after the T-junction using three mesh levels (fine, medium, coarse).

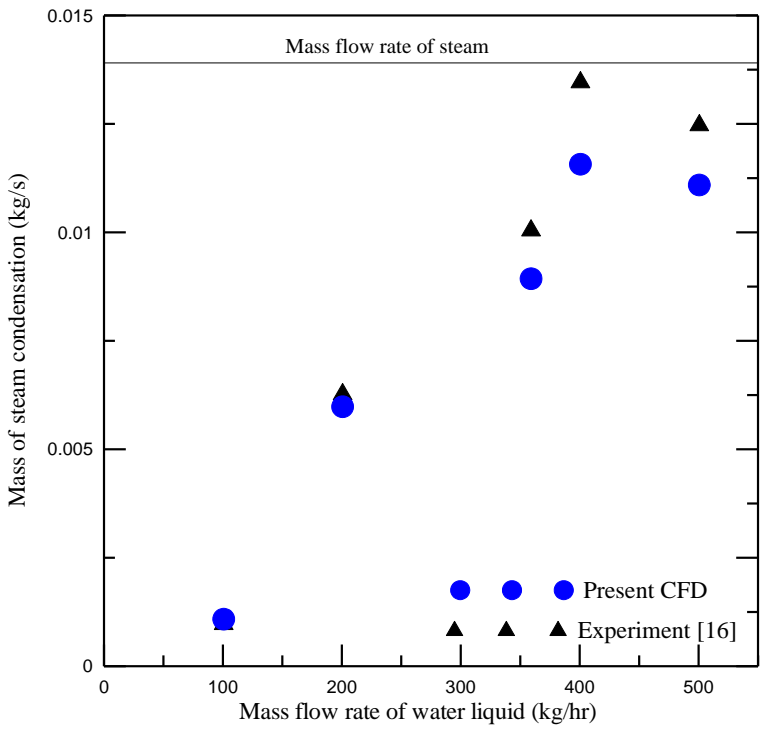

Figure (5) Validation of the present two phase flow model with the experimental data reported in [16]

\section{Results and Discussion}

Condensation of two-phase flow inside a tube shows a complicated phenomenon that affects both the pressure drops from upstream to downstream and the void fraction distribution in the pipe. This phenomenon always appears in the T-junction which is a kind of piping structure found in nuclear and steam power plants. The investigation of two-phase flow in this structure helps to predict the hydrodynamic phenomenon of heat and mass transfer in mixing undergoing condensation.

In the present study, two cases for the T-pipe are considered. In the first case, Case 1, the branch angle $(\theta)$ is $90^{\circ}$ while in the second case, Case 2, the angle is $45^{\circ}$, where $\theta$ is the oblique branch angle and it is measured between the water liquid and steam flow directions in the main and branch pipes, respectively. Also, more operational conditions are trained for both cases and tested to fit the limiting condition for the condensation rate in the $\mathrm{T}$-junction with the considered two angles. These limiting conditions were found to be $0.1-0.4 \mathrm{~kg} / \mathrm{s}$ for the water liquid mass flow rate and mass ratio $\left(\dot{\boldsymbol{m}}_{\boldsymbol{w}} / \dot{\boldsymbol{m}}_{\boldsymbol{s}}\right)$ in the range of 500-2500. The results are presented for the whole $\mathrm{T}$-junction to track the flow contours inside the whole domain. The mass flow rates of both fluids are kept constant for both cases.

\subsection{Results for Case 1}

Figure (6) describes the steam mass flow rate influence on the contours of pressure at $m_{w}=0.1 \mathrm{~kg} / \mathrm{s}$ and $\theta=90^{\circ}$. The static pressure decreases towards the mixing point. Also, the static pressure continues 


\section{Khaled Yousef, Fatma Saleh and Ahmed Hegazy "Numerical Study of Induced Condensation upon Mixing Flows of Water-Steam Flow in a Tee-Junction Pipe”}

to decrease towards the tee exit due to rapid bulk condensation as a result of steam/water liquid mixing. Steam condensation generates a vacuum region inside the pipe as a result of large specific volume differences of water liquid and steam. Hence, a more steam flow rate results in more condensation inside the T-pipe which generates more vacuum inside the pipe. The generated vacuum decreases the static pressure inside the pipe. This can be seen in Figure (6.d) that achieves the lowest outlet pressure compared to the other conditions for lower steam mass flow rates, see Figures (6.a, 6.b, and 6.c).

Figure (7) describes the temperature fluctuations that occur due to rapid bulk condensation in the mixing region. The temperature decreases towards the T-pipe exit due to steam to water liquid mass transfer at $\dot{m}_{s}=0.0002 \mathrm{~kg} / \mathrm{s}$ as shown in Figure (7.d). The temperature fluctuations increase when the value of $\dot{m}_{s}$ rises due to the thermal mixing of water liquid and steam at a big temperature difference. At the end of the T-pipe, all steam is turned into water and the exit temperature is raised due to steam latent heat release. Also, the temperature stripping is easily appeared around the mixing region in Figure (7.d). This temperature stripping magnifies with the steam mass flow rate increases.

Figure (8) shows the water liquid volume fraction contours at $\theta=90^{\circ}$ and $m \dot{w}=0.1 \mathrm{~kg} / \mathrm{s}$. It is obvious from Figure (8) that steam is converted to water liquid due to bulk condensation and it releases its latent heat in the mixing region. Figures (8.c) and (8.d) show the zone of flow recirculation beyond the steam emerging region. This generated circulation delays the two fluids mixing in the pipe top immediately downstream the T-connection. Figure (8.d) shows shed light on the effects of the rising value of $\dot{m}_{s}$ and makes them more pronounced. Increasing the steam mass flow rate makes the steam takes a longer distance from the mixing region to be condensed, i.e. delayed mixing. Moreover, in some cases, steam may reach the duct exit without condensation due to high water velocity or high steam mass flow rate. The mixing length is a highly turbulent region and it is mainly affected by the mass ratio between the water liquid and steam.

Figures (9) and (10) show mass transfer rate and volume fraction distributions in pipe cross-sections at $x=1 D_{\text {in }}, x=3 D_{\text {in }}$, and $x=5 D_{\text {in }}$, respectively, where $x$ is the axial distance measured beyond the mixing point on the pipe centerline. The blue color represents the highest value while the red color indicates the lower value for all figures. Volume fraction distribution in Figure (10.a) shows a rather sharp stratification of the steam with water liquid at the locations of $1 D_{\text {in }}$ and slightly at $3 D_{\text {in }}$ in Figure (10.b). This sharp stratification can be easily noticed near the upper pipe wall after the mixing region of the T-pipe. In Figures (9.c and 10.c) at $x=5 D_{\text {in }}$, the enhanced turbulent mixing has led to steam penetration of steam into the flow and more condensation rates can occur. Furthermore, Figures (9.c and 10.c) show the pronounced and progressed mixing at $x=5 D_{\text {in }}$ where the averaged mass transfer and steam volume fraction are well below the upper sidewalls of the pipe cross-section and detached from the upper walls, this is due to the buoyancy effect and wall condensation.

The path-line of turbulent mixing is an indicator of the degree of interaction between two streams. The path-line interactions can be visualized by the intense intersected lines at higher mixing. Figure (11) shows the path-line mixing at $x=1 D_{i n}, 3 D_{n i}$ and $5 D_{i n}$ that indicate more interactions and mixing at $x=1 D_{\text {in }}$. Figure (11) illustrates the region of flow recirculation beyond the steam penetration. As noticed in the previous case, this circulation retards the two flows blending at the top of the pipe after the T-junction. The steam volume fraction of the pipe top wall at $x=$ $1 D_{\text {in }}$ suggests quite a high concentration near the inlet of the branch pipe and then the steam volume fraction decreases with axial distance due to its condensation at $x=3 D_{\text {in }}$ and $5 D_{\text {in }}$. Also, the buoyancy effect due to the density gradient is noticed in Figures (10.a and 10.b). 


upon Mixing Flows of Water-Steam Flow in a Tee-Junction Pipe”
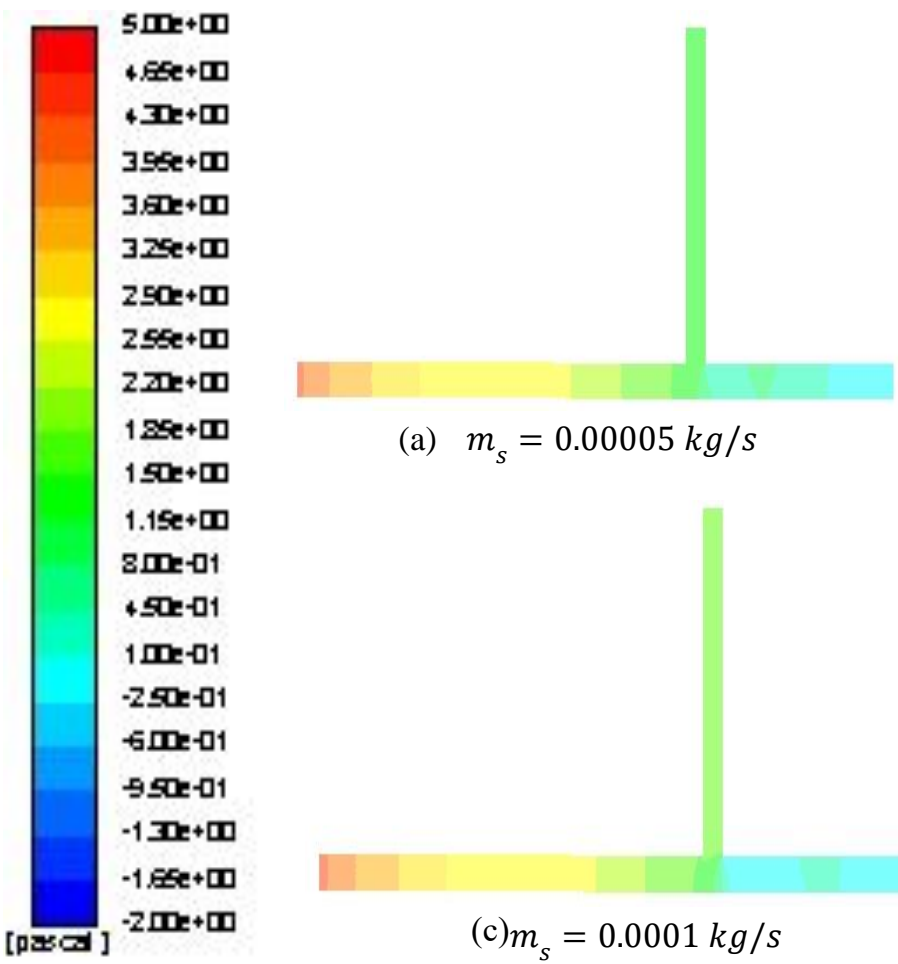

(a) $m_{s}=0.00005 \mathrm{~kg} / \mathrm{s}$

(b) $m_{s}=0.0000667 \mathrm{~kg} / \mathrm{s}$
(c) $m_{s}=0.0001 \mathrm{~kg} / \mathrm{s}$
(d) $m_{s}=0.0002 \mathrm{~kg} / \mathrm{s}$

Figure (6) Contours of mixture static pressure for Case 1 at $\dot{m}_{w}=0.1 \mathrm{~kg} / \mathrm{s}$ and different steam mass flow rates

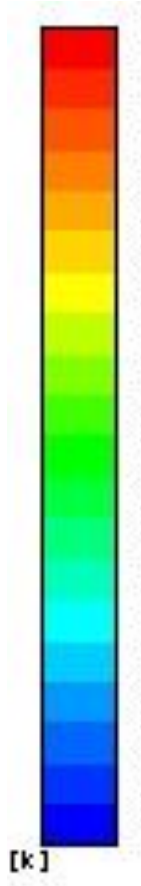

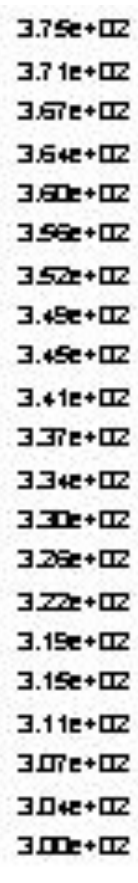

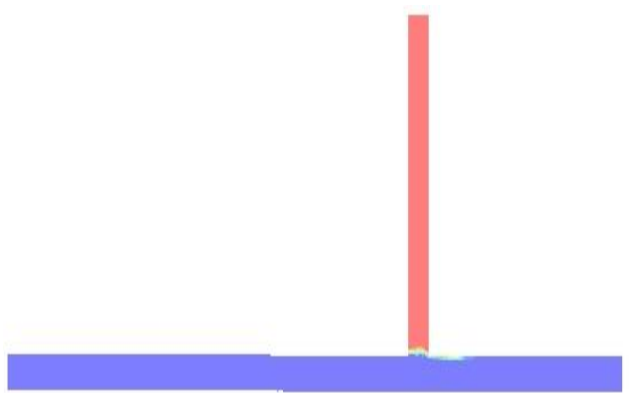

(a) $m_{s}=0.00005 \mathrm{~kg} / \mathrm{s}$

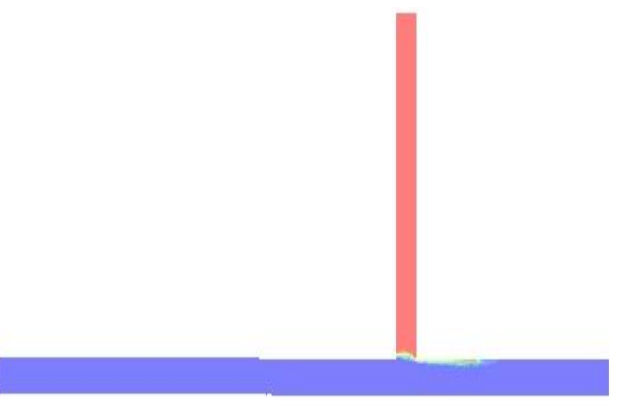

(c) $m_{s}=0.0001 \mathrm{~kg} / \mathrm{s}$

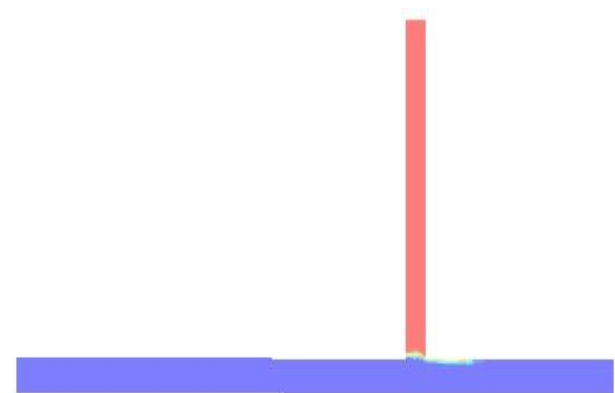

(b) $m_{s}=0.0000667 \mathrm{~kg} / \mathrm{s}$

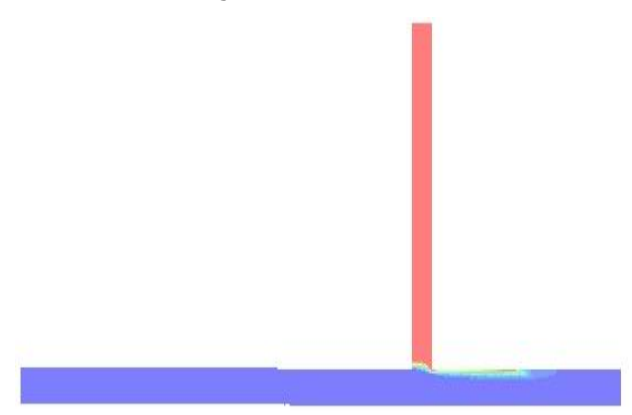

(d) $m_{s}=0.0002 \mathrm{~kg} / \mathrm{s}$

Figure (7) Contours of mixture static temperature for Case 1 at $\dot{m}_{w}=0.1 \mathrm{~kg} / \mathrm{s} \&$ different steam mass flow rates 

upon Mixing Flows of Water-Steam Flow in a Tee-Junction Pipe”

1.00
0.95
0.90
0.85
0.80
0.75
0.70
0.65
0.60
0.55
0.50
0.45
0.40
0.35
0.30
0.25
0.20
0.15
0.10
0.05
0.00

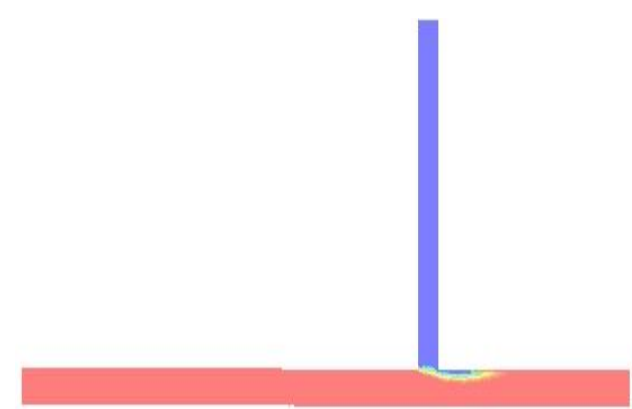

(a) $m_{s}=0.00005 \mathrm{~kg} / \mathrm{s}$

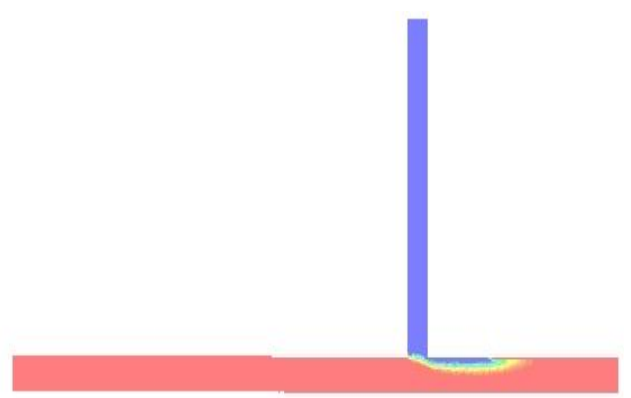

(c) $m_{s}=0.0001 \mathrm{~kg} / \mathrm{s}$

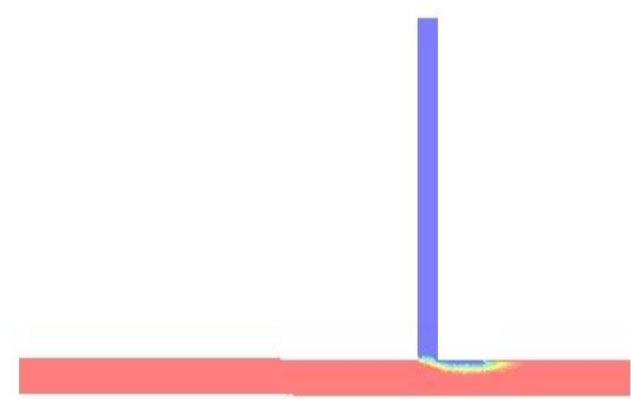

(b) $m_{s}=0.0000667 \mathrm{~kg} / \mathrm{s}$

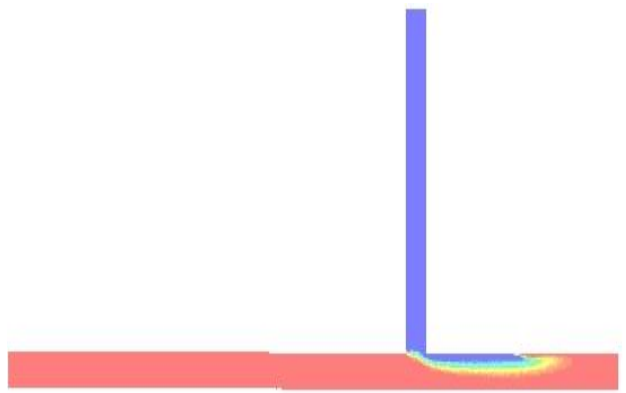

(d) $m_{s}=0.0002 \mathrm{~kg} / \mathrm{s}$

Figure (8) Contours of the water liquid volume fraction of Case 1 at $m_{w}=0.1 \mathrm{~kg} / \mathrm{s}$ and different steam mass flow rates
B.
$-4.92 e-102$
$-9.93 e-02$
$-1 \cdot 49 e-101$
$-1.99 e-101$
$-2.49=-101$
$-2.99 \mathrm{e}-101$
$-3.49 e-\square 1$
-4. 00 e-101
-4.50e-11
$-5.00 e-01$
$-5.50 e-01$
$-6.00 \mathrm{e}-\mathrm{D1}$
-6. 50 e- $\square 1$
$-7.00 \mathrm{a}-\mathrm{a}$
$-7.50 \mathrm{e}-\mathrm{01}$
-8. 00 e-101
-8.50e-口
-9.00 e- 01
$-9.50-101$
-1.00 e +

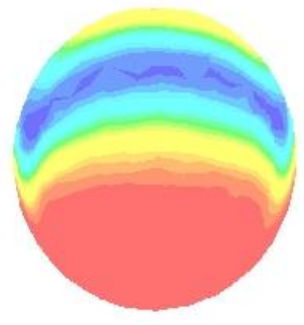

(a) $1 D_{\text {in }}$

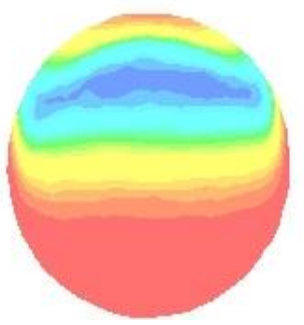

(b) $3 D_{\text {in }}$

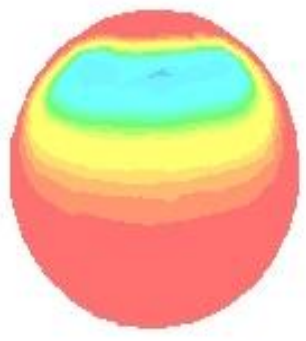

(c) $5 D_{\text {in }}$

Figure (9) Cross-sectional distribution of the mass transfer contours for Case 1 at $m_{w}=0.1 \mathrm{~kg} / \mathrm{s}$ and $m_{s}=0.002 \mathrm{~kg} / \mathrm{s}$ along the main exit pipe 


\section{Khaled Yousef, Fatma Saleh and Ahmed Hegazy "Numerical Study of Induced Condensation upon Mixing Flows of Water-Steam Flow in a Tee-Junction Pipe"}
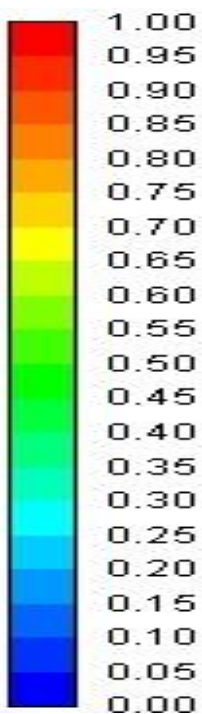

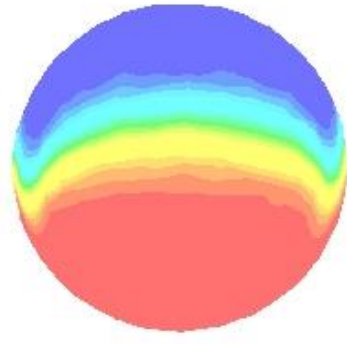

(a) $1 D_{\text {in }}$

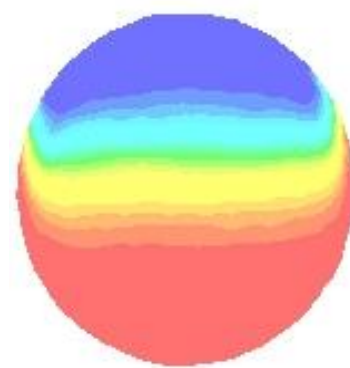

(b) $3 D_{\text {in }}$

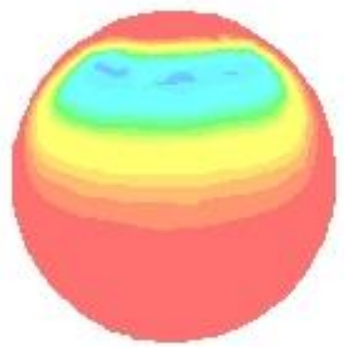

(c) $5 D_{\text {in }}$

Figure (10) Cross-sectional distribution of the water liquid volume fraction contours for Case 1 at $m_{w}=0.1 \mathrm{~kg} / \mathrm{s}$ and $m_{s}=0.002 \mathrm{~kg} / \mathrm{s}$ along the main exit pipe

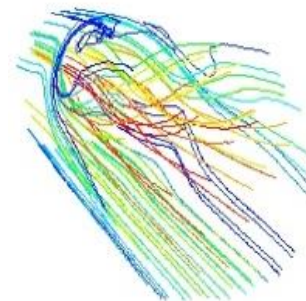

a) $1 D_{\text {in }}$

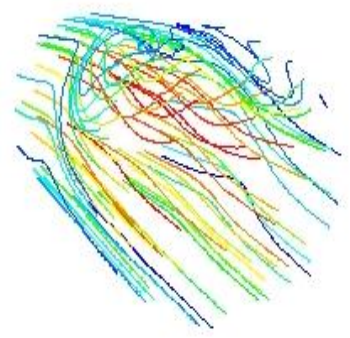

(b) $3 D_{\text {in }}$

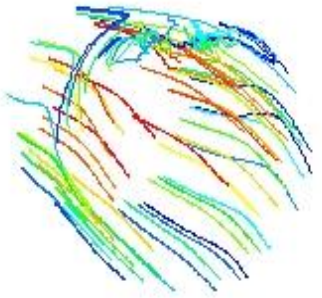

(c) $5 D_{\text {in }}$

Figure (11) Pathline turbulent mixing behind the T-junction for Case 1 at $m_{w}=0.1 \mathrm{~kg} / \mathrm{s}$ and $m_{s}=0.002 \mathrm{~kg} / \mathrm{s}$ along the main exit pipe

\subsection{Results for Case 2}

In this case of inclined mixing, the oblique branch pipe angle $(\theta)$ between the water inflow steam pipes is $45^{\circ}$. For Case 2, the computations are executed for the same conditions considered for Case 1 . Furthermore, we will introduce the same operational conditions for Case 2. Then, more results will be documented and tabulated for comparison as will be seen later in Table (1).

In this session, the effect of the inclined mixing will be described and compared with the perpendicular $\mathrm{T}$ junction (case $1, \theta=90^{\circ}$ ). The inclined branch offers more direct contact condensation and increased the area of heat transfer between the interface of the water liquid and steam, as predicted previously by $[8,11]$. Figure (12) describes the effect of increasing the steam mass flow rate on the static pressure contours at $\theta=45^{\circ}$ at $m_{w}=0.1 \mathrm{~kg} / \mathrm{s}$. It is clear from Figure (12) that the static pressure values decrease towards the T-pipe exit, due to the same reasons explained previously. The contours of the static temperature and liquid volume fractions for the same conditions are described in Figures (13) and (14), respectively. The temperature fluctuations can be seen at different mass flow rate ratios. Furthermore, it is noticed that steam with high temperature is diffused along the pipe walls due to this interrupted mixing, which results in a hightemperature fluid, as seen in Figure (13.d) at $\theta=45^{\circ}$. The inclined angle increases the area of thermal mixing between the liquid water and steam 


\section{Khaled Yousef, Fatma Saleh and Ahmed Hegazy "Numerical Study of Induced Condensation upon Mixing Flows of Water-Steam Flow in a Tee-Junction Pipe"}

which can be seen in Figure (13.d). The Crosssectional distribution of mass transfer and volume fraction of $x=1 D_{i n}, 3 D_{i n}$, and $5 D_{i n}$ for Case 2 are shown in Figures (15) and (16), respectively. The steam and water liquid stratification can be easily observed in Figures (16.a and 16.b) with the buoyancy force effects. It is obvious from Figure (17) that the recirculation zone due to mixing is not delayed in Case 2 compared to the same results for Path-line in Case 1. These results in rapid mixing after the $\mathrm{T}$-junction lead to a slight fast condensation compared to Case 1. This can be clarified by comparing the volume fraction contours at the same cross-section and location for Cases 1 and 2 in Figures (10) and (16), respectively. Figure (18) describes the effect of pipe cross sectional area on the water liquid volume fraction inside the $\mathrm{T}$-junction pipe. It is obvious that rising the pipe diameter at the same steam and water liquid mass flow rates enhances the condensation at the mixing region. This may be attributed to the flow velocity decreasing which gives more time for the steam to be mixed and condensed. At lower steam mass flow rates and bigger pipe diameter, the water liquid can be slightly drawn by the vacuum generated due to the condensation in the branch pipe as shown in Figure (18-f).

In this section, we will discuss the condensation mixing length. This length is the required length to condense all the inflow steam before the T-junction exit. The condensation mixing length depends mainly on the water liquid/steam mass flow rate ratio and mixing angle. The condensation ratio of the T-pipe exit can be used as an indicator for the condensation performance and this ratio can be calculated by Eq. .(12)

Condensation ratio at T-pipe exit $=100 *(1-$

$$
\left(\frac{m_{s} \text { at T-pipe exit }}{m_{s} \text { at T-pipe inlet }}\right)
$$

When the condensation ratio is equal to $100 \%$, it means that all steam entering the T-junction is converted into water liquid, fully condensation at the T-pipe exit. Lower values of condensation ratio indicate that steam still exits from the $\mathrm{T}$-junction without condensation; in this case, the mixing length is not sufficient for the completely steam condensation as shown in Table (1). It is clear from Table (1) that a $\mathrm{T}$-junction with $45^{\circ}$ has a higher condensation ratio at its exit for the same water liquid/steam mass flow rate ratios compared to $90^{\circ} \mathrm{T}$ junction. T-junction with an angle of $45^{\circ}$ provides more water/steam mixing capability and surface contacting which achieve higher condensation rates compared to the T-junction with an angle of $90^{\circ}$ branch.

Table (1) Condensation ratio at the T-junction exit for Case 1 and Case 2

\begin{tabular}{|c|c|c|c|}
\hline \multirow[t]{2}{*}{$\dot{m}_{w}$} & \multirow[t]{2}{*}{$\dot{m}_{w} / \dot{m}_{s}$} & \multicolumn{2}{|c|}{$\begin{array}{c}\text { Condensation ratio at T-pipe } \\
\text { exit }(\%)\end{array}$} \\
\hline & & $\begin{array}{l}\text { ase } 1 C \\
\theta=90^{\circ}\end{array}$ & $\begin{array}{l}\text { ase } 2 C \\
\theta=45^{\circ}\end{array}$ \\
\hline \multirow{5}{*}{0.1} & 2500 & 100 & 100 \\
\hline & 2000 & 100 & 100 \\
\hline & 1500 & 100 & 100 \\
\hline & 1000 & 100 & 100 \\
\hline & 500 & 100 & 100 \\
\hline \multirow{5}{*}{0.25} & 2500 & 99.8 & 99.9 \\
\hline & 2000 & 99.6 & 99.8 \\
\hline & 1500 & 99.2 & 97.8 \\
\hline & 1000 & 97.9 & 98.5 \\
\hline & 500 & 87.4 & 89.7 \\
\hline \multirow{5}{*}{0.4} & 2500 & 97.2 & 98.20 \\
\hline & 2000 & 95.9 & 97.1 \\
\hline & 1500 & 93.3 & 94.8 \\
\hline & 1000 & 78.2 & 89 \\
\hline & 500 & 63.9 & 66.6 \\
\hline
\end{tabular}




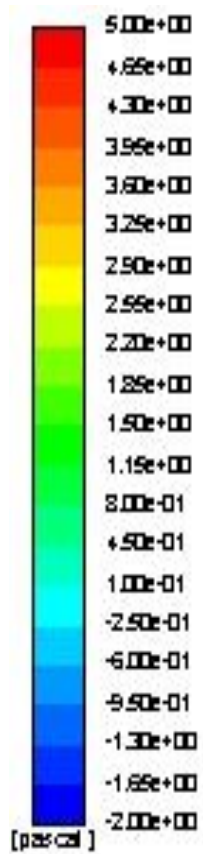

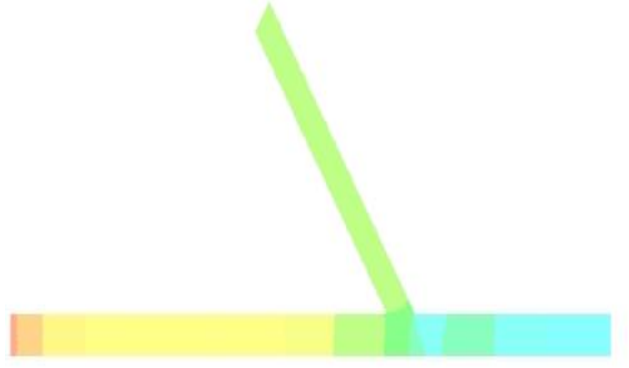

(a) $\mathrm{m}_{\mathrm{s}}=0.00005 \mathrm{~kg} / \mathrm{s}$

(b) $\mathrm{m}_{\mathrm{s}}=0.000667 \mathrm{~kg} / \mathrm{s}$

(c) $\mathrm{m}_{\mathrm{s}}=0.0001 \mathrm{~kg} / \mathrm{s}$

(d) $\mathrm{m}_{\mathrm{s}}=0.0002 \mathrm{~kg} / \mathrm{s}$

Figure (12) Contours of the mixture static pressure for Case at $m_{w}=0.1 \mathrm{~kg} / \mathrm{s}$ and different values of steam mass flow rates

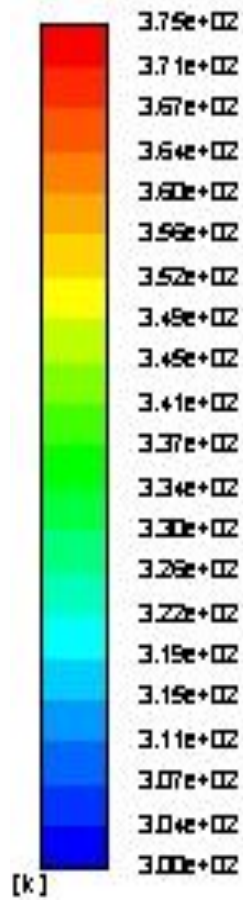

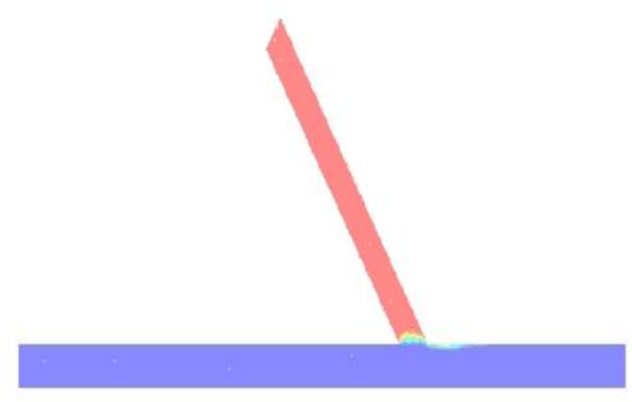

(a) $\mathrm{m}_{\mathrm{s}}=0.00005 \mathrm{~kg} / \mathrm{s}$

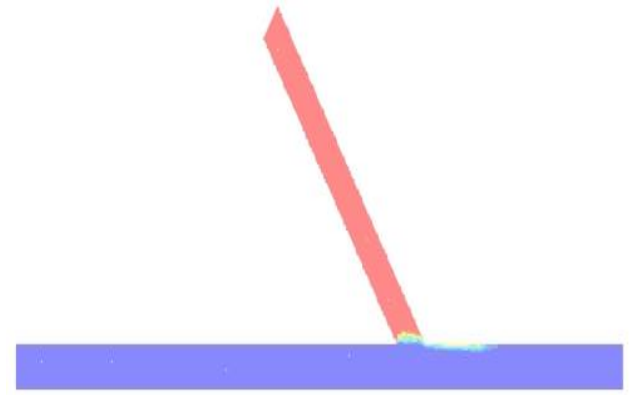

(c) $\mathrm{m}_{\mathrm{s}}=0.0001 \mathrm{~kg} / \mathrm{s}$

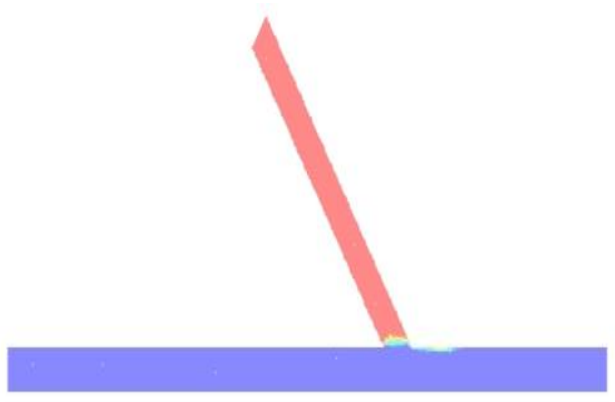

(b) $\mathrm{m}_{\mathrm{s}}=0.000667 \mathrm{~kg} / \mathrm{s}$

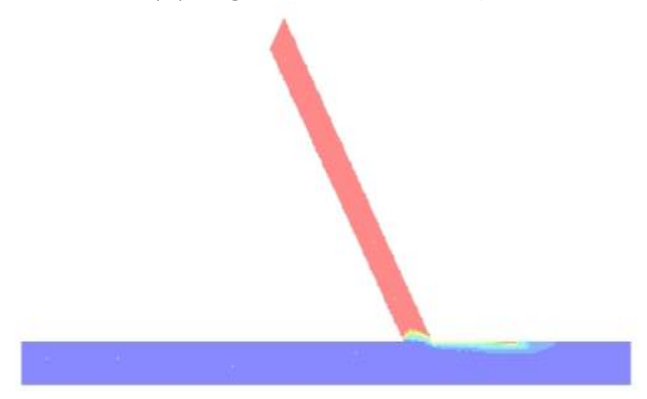

(d) $\mathrm{m}_{\mathrm{s}}=0.0002 \mathrm{~kg} / \mathrm{s}$

Figure (13) Contours of the mixture static temperature for Case 2 at $m_{w}=0.1 \mathrm{~kg} / \mathrm{s}$ and different values of steam mass flow rates 

upon Mixing Flows of Water-Steam Flow in a Tee-Junction Pipe”

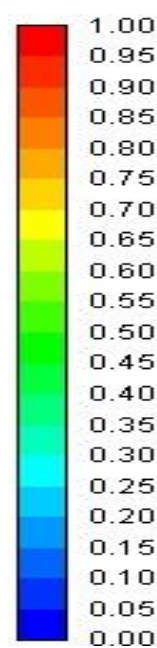

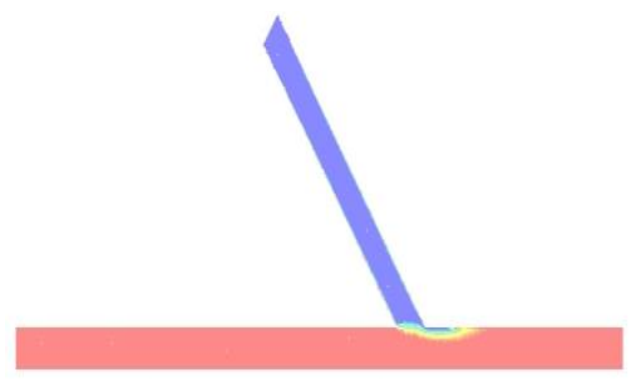

(a) $\mathrm{m}_{\mathrm{s}}=0.00005 \mathrm{~kg} / \mathrm{s}$

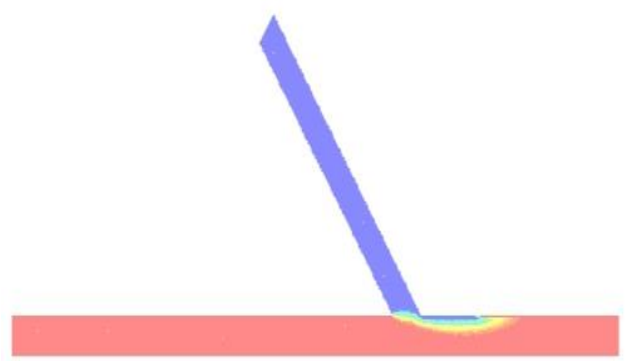

(c) $\mathrm{m}_{\mathrm{s}}=0.0001 \mathrm{~kg} / \mathrm{s}$

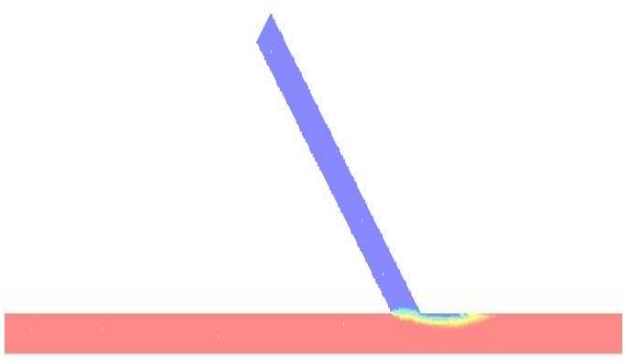

(b) $\mathrm{m}_{\mathrm{s}}=0.0000667 \mathrm{~kg} / \mathrm{s}$

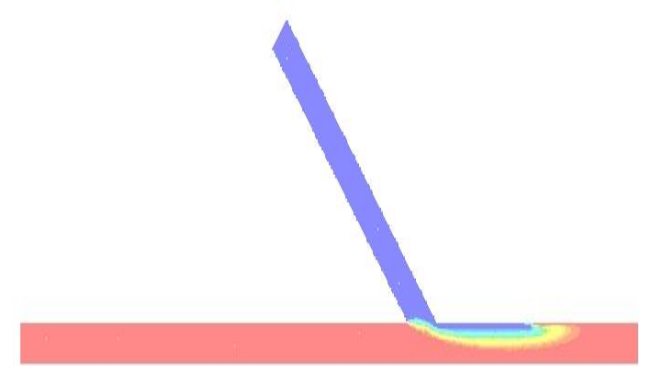

(d) $\mathrm{m}_{\mathrm{s}}=0.0002 \mathrm{~kg} / \mathrm{s}$

Figure (14) Water liquid volume fraction contours for Case 2 at $m_{w}=0.1 \mathrm{~kg} / \mathrm{s}$ and different values of steam mass flow rates

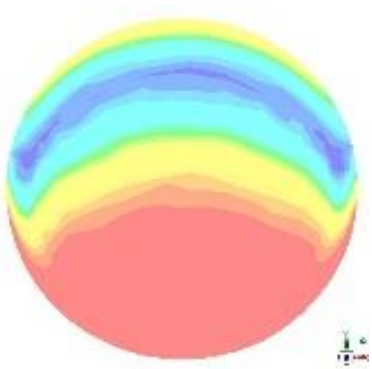

(a) $1 D_{\text {in }}$

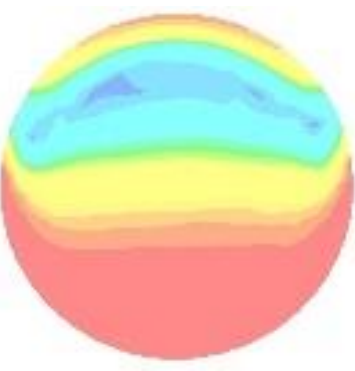

(b) $3 D_{\text {in }}$

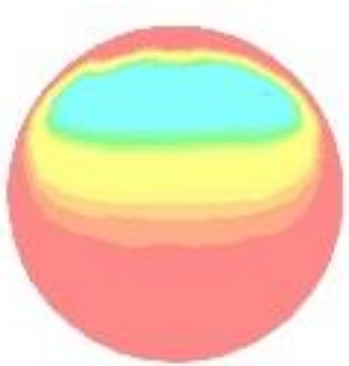

(c) $5 D_{\text {in }}$

Figure (15) Cross-sectional distribution of mass transfer contours for Case 2 at $m_{w}=0.1 \mathrm{~kg} / \mathrm{s}$ and

$$
m_{s}=0.002 \mathrm{~kg} / \mathrm{s} \text { along the main exit pipe }
$$



upon Mixing Flows of Water-Steam Flow in a Tee-Junction Pipe”

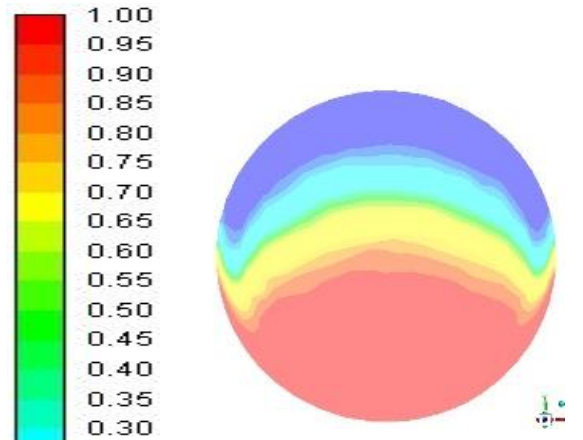

(a) $1 D_{\text {in }}$

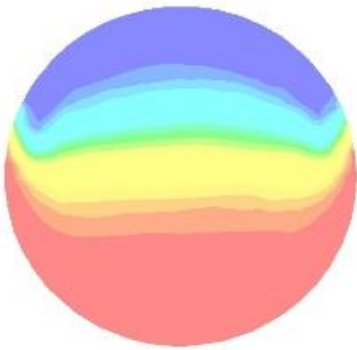

(b) $3 D_{\text {in }}$

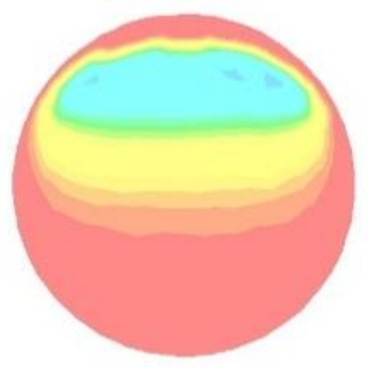

(c) $5 D_{\text {in }}$

Figure (16) Cross-sectional distribution of water liquid volume fraction contours for Case 2 at $m_{w}=0.1 \mathrm{~kg} / \mathrm{s}$ and $m_{s}=0.002 \mathrm{~kg} / \mathrm{s}$ along the main exit pipe

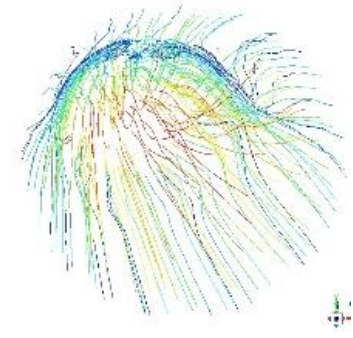

(a) $1 D_{\text {in }}$

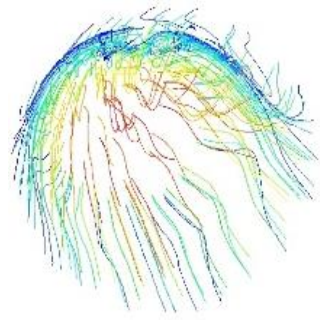

(b) $3 D_{\text {in }}$

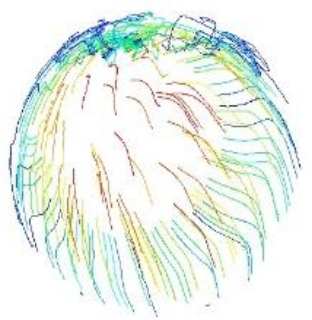

(c) $5 D_{\text {in }}$

Figure (17) Pathline turbulent mixing behind the T-junction for Case 2 at $m_{w}=0.1 \mathrm{~kg} / \mathrm{s}$ and $m_{s}=0.002 \mathrm{~kg} / \mathrm{s}$ along the main exit pipe

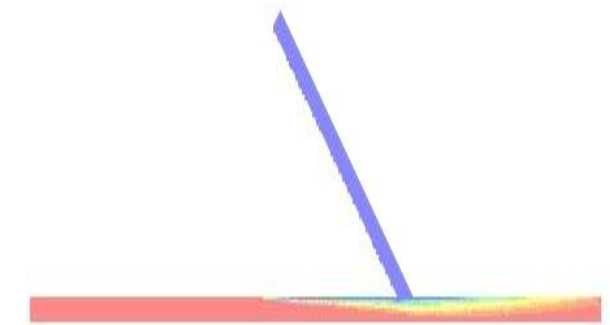

(a) $D_{p}=30 \mathrm{~mm}, \mathrm{~m}_{\mathrm{s}}=0.0001 \mathrm{~kg} / \mathrm{s}$

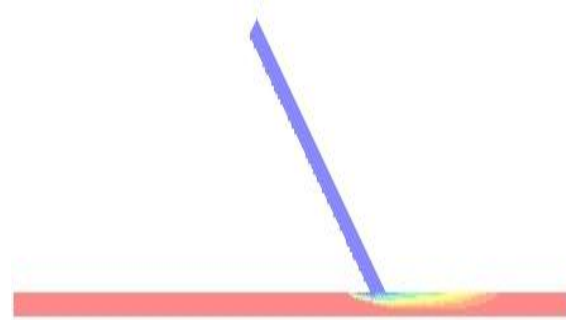

(b) $D_{p}=30 \mathrm{~mm}, \mathrm{~m}_{\mathrm{s}}=0.00005 \mathrm{~kg} / \mathrm{s}$ 


\section{Khaled Yousef, Fatma Saleh and Ahmed Hegazy "Numerical Study of Induced Condensation upon Mixing Flows of Water-Steam Flow in a Tee-Junction Pipe”}

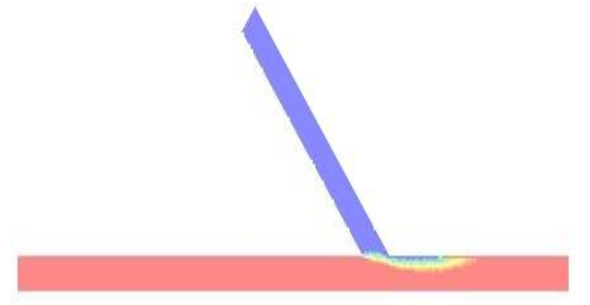

(c) $D_{p}=50 \mathrm{~mm}, \mathrm{~m}_{\mathrm{s}}=0.0001 \mathrm{~kg} / \mathrm{s}$

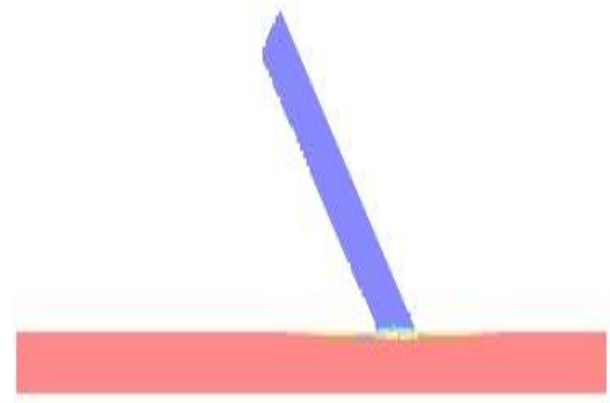

(e) $D_{p}=70 \mathrm{~mm}, \mathrm{~m}_{\mathrm{s}}=0.0001 \mathrm{~kg} / \mathrm{s}$

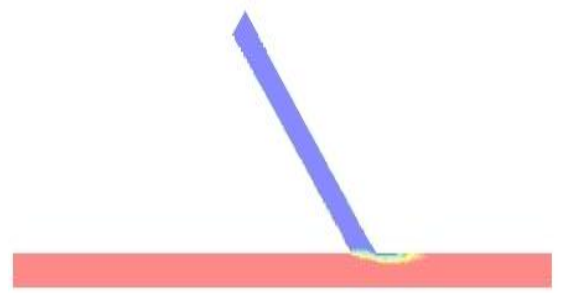

(d) $D_{p}=50 \mathrm{~mm} \mathrm{~m}$ s $=0.00005 \mathrm{~kg} / \mathrm{s}$

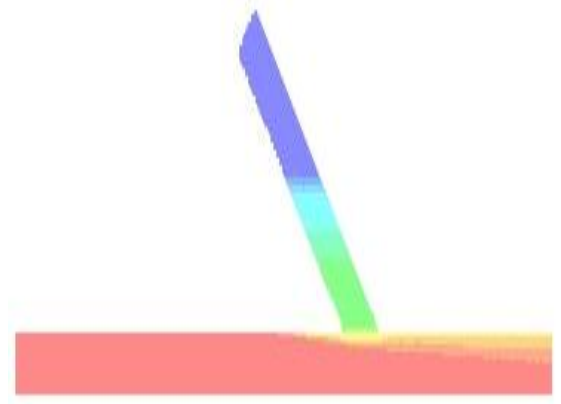

(f) $D_{p}=70 \mathrm{~mm} \mathrm{~m}$ s $=0.00005 \mathrm{~kg} / \mathrm{s}$

Figure (18) effect of pipe cross sectional area on the water liquid volume fraction contours for Case 2

$$
\text { at } m_{w}=0.1 \mathrm{~kg} / \mathrm{s}
$$

\section{Conclusions}

In the present study, a T-junction pipe with two oblique angles between the primary water liquid and branched steam inflows is numerically investigated. The effects of mass flow rate ratios between the two streams are discussed. Distributions of the static pressure, temperature and volume fraction as a result of water-steam mixing and steam condensation were taken into account. The results show that there is more flow fluctuation and the temperature fluctuations may be producing a high turbulent flow in the mixing region which should be considered when designing the T-pipe. Besides, the T-pipes with both angles $45^{\circ}$ and $90^{\circ}$ show relatively the same condensation rate at the lowest considered water liquid mass flow rate of $0.1 \mathrm{~kg} / \mathrm{s}$ and water liquid/steam mass ratio of 500 or more. By increasing the water liquid mass rate to $0.25 \mathrm{~kg} / \mathrm{s}$, T-junction with an angle of $45^{\circ}$ shows an improved condensation rate compared to T-junction with $90^{\circ}$ at a mass ratio of 2500 and less. To reach a full condensation of the steam at the pipe outlet for both angles of T-junction with a water liquid mass flow rate of $0.4 \mathrm{~kg} / \mathrm{s}$, a minimum mass ratio of water liquid/steam of 3000 is required. Furthermore, the T-junction with an angle of $45^{\circ}$ can condense all the mixed steam at the duct outlet with lower pressure loss under the same operational conditions as the $90^{\circ} \mathrm{T}$-pipe.
Also, a T- junction with an angle of $45^{\circ}$ may improve the recirculation area resulting after the junction and therefore better performance occurs. Also, increasing the T-junction pipe diameters gives rise to notably improving the mixing process and enhancement in steam condensation.

$\begin{array}{ll}\text { Nomenclature } \\ D & \text { pipe diameter }(\mathrm{m}) \\ E & \text { total Energy }(\mathrm{kJ}) \\ h & \text { enthalpy }(\mathrm{kJ} / \mathrm{kg} \mathrm{K}) \\ k & \text { turbulent kinetic energy }\left(\mathrm{m}^{2} / \mathrm{s}^{2}\right) \\ K & \text { thermal conductivity }(\mathrm{W} / \mathrm{m} . \mathrm{K}) \\ L & \text { length of the pipe }(\mathrm{m}) \\ \cdot & \text { mass flow rate }(\mathrm{kg} / \mathrm{s}) \\ p & \text { pressure }(\mathrm{kPa}) \\ p & \text { Reynolds number }(-) \\ \text { Re } & \text { temperature }(\mathrm{K}) \\ T & \text { axial mean velocity }(\mathrm{m} / \mathrm{s}) \\ u & \text { radial mean velocity }(\mathrm{m} / \mathrm{s}) \\ v & \text { tangential mean velocity }(\mathrm{m} / \mathrm{s}) \\ w & \text { volume fraction }(-) \\ \text { Greek letters } \\ \alpha & \text { turbulent dissipation rate }\left(\mathrm{m}^{2} / \mathrm{s}^{3}\right) \\ \varepsilon & \text { dynamic viscosity }(\mathrm{kg} / \mathrm{m} . \mathrm{s}) \\ \mu & \text { turbulent viscosity }(\mathrm{kg} / \mathrm{m} . \mathrm{s}) \\ \mu_{t} & \text { effective viscosity }(\mathrm{kg} / \mathrm{m} . \mathrm{s}) \\ \mu_{e f f} & \text { density }\left(\mathrm{kg} / \mathrm{m}^{3}\right) \\ \rho & \\ \Omega_{i j} & \text { mean rate of rotation tensor }(-)\end{array}$




\section{Khaled Yousef, Fatma Saleh and Ahmed Hegazy "Numerical Study of Induced Condensation upon Mixing Flows of Water-Steam Flow in a Tee-Junction Pipe”}

$\theta$

inclination branch angle of the T-junction

between main and branch pipes

\section{Subscripts}

in inner

$m \quad$ mixture

ref reference

$p \quad$ pipe

$s \quad$ steam

w water liquid

\section{References}

[1] M. Holloway, C. Nwaoha, O. A. Onyewuenyi, "Process Plant Equipment: Operation, Control, and Reliability", DOI: 10.1002/9781118162569, John Wiley and Sons, 2012

[[2] U. Anderson, J. Westin, J. Eriksson, "Thermal Mixing in a T-Junction. Model Tests 2006", Report Number U 06:66, Vattenfall R\&D AB, Älvkarleby, Sweden, 2006, pp. 1-68.

[3] Th. Frank, M. Adlakha, C. Lifante, H. M.,Prasser, and F. Menter, "Simulation of turbulent and thermal mixing in T-junctions using URANS and scale-resolving turbulence models in ANSYS CFX", Nuclear engineering and Design 240(9):2313-2328, 2010.

[4] M. Benyamina, P. Knyazkov, O. Imine, "Large eddy simulation of thermal turbulent mixing and reduction of temperature fluctuations with swirl in T-junction", Journal of the Brazilian Society of Mechanical Sciences and Engineering, Vol. 39, No. 3, 2017.

[5] Y. Masuda, T. Aizawa, and A. Suzuki," Flow Visualization and Numerical Simulation of Tjunction Mixing of High-Temperature HighPressure Water", J. of chemical engineering of Japan, Vol. 42, No. 2 pp. 64-70, 2009.

[6] M. Chen, H. Hsieh, Z. Zhang, and B. Pei, "Experimental investigation of thermal mixing phenomena in a tee pipe", Kerntechnik, Vol. 80 No. 2, p. 116-123, 2015.

[7] T. Maruyama, S. Suzuki, and T. Mizushina, "Pipeline Mixing between Two Fluid streams Meeting at a T-Junction", Int. Chem. Eng., Vol. 21, No. 205, 1981.

[8] T. Maruyama, T. Mizushina, and, F. Watanabe, "Turbulent mixing of two fluid streams at an oblique branch" International Chemical Engineering, Vol. 22, No. 2, pp. 287-294, 1982.

[9] T. Maruyama, T. Mizushina, and S. Hayashiguchi, "Optimum conditions for jet mixing in turbulent pipe flow", International Chemical Engineering, Vol. 23, No. 4, 1983.

[10] S. M. Hosseini, K. Yuki, and H. Hashizume, "Classification of turbulent jets in a T-junction area with a 90-deg bend upstream ",
International Journal of Heat and Mass Transfer, Vol. 51, No. 9, pp. 2444-2454, 2008.

[11] H. Zughbi, "Effects of Jet Protrusion on Mixing in Pipelines with Side-tees", Chemical Engineering Research and Design, Vol. 84, No. 11, pp. 993-1000, 2006.

[12] R. Zboray, A. Manera, B. Niceno, and H. M.Prasser, "Investigations on Mixing Phenomena in Single-phase Flows in a TJunction Geometry", the $12^{\text {th }}$ Int. Topical Meeting on Nuclear Reactor Thermal Hydraulics (NURETH-12), Sheraton Station Square, Pittsburgh, Pennsylvania, USA, 2007, Paper No. 71, pp. 1-20.

[13] A. Hegazy, M. Hegazy, and A. Engeda, "A novel desalination system for utilizing waste heat contained in cooling salt water of a steam plant condenser", Desalination, Vol. 371, pp.58-66, 2015.

[14] G. B. Nimadge, S. V. Chopade, "CFD analysis of flow through T-junction of pipe", international Research Journal of Engineering and Technology, Vol. 4, No. 2, pp. 906-911, 2017.

[15] N. A. Ferede, "Numerical analysis and CFD simulation of fluid flow in T-Junction pipe By using ANSYS CFX", International Journal of Scientific \& Engineering Research Vol 10, No 10, pp. 504-513, 2019

[16] W.Y .Ren, G. J. Yu, J. W. ,Bian, W. X. Tian, G. H. Su, S. Z. Qiu, X. L. Fu, "Experiment of Condensation in T-junction: Steam-water Flow in Water-injected Condition", NURETH-16, Chicago, IL, August 30-September 4, 2015.

[17] Ansys Fluent 18.1 theory's guide, 2018

[18] H. K. Versteeg, and W. Malalasesekera, “An introduction to computational fluid dynamics, the finite volume method", Pearson Education Limited, England, $2^{\text {nd }}, 2007$.

[19] T. H. Shih, W. W. Lou, A. Shabbir, Z. Yang, and J. Zhou, "A new k-e eddy viscosity model for high Reynolds number turbulent flow-model development and validation", Computer Fluids Vol. 24, No. 3, pp. 227-238, 1995.

[20] Li J. De, "CFD simulation of water vapor condensation in the presence of non-condensable gas in vertical cylindrical condensers", International Journal of Heat and Mass Transfer, Vol .57, pp. 708-721, 2013

[21] S. Chen, Z. Yang, Y. Duan, Y. Chen, and D. $\mathrm{Wu}$, "Simulation of condensation flow in a rectangular microchannel", Chemical engineering and Processing, Vol. 76, pp.. 60-69, 2014. 